\title{
Improved survival rate and functional recovery of TKA in cementless fixation compared with cemented component: a systematic review and meta-analysis
}

Yuan Liu

Sichuan University West China Hospital

Yi Zeng

Sichuan University West China Hospital

Yuangang Wu

Sichuan University West China Hospital

Mingyang Li

Sichuan University West China Hospital

Huiqi Xie

Sichuan University West China Hospital

Bin Shen ( $\square$ shenbin_1971@163.com )

West China Hospital, Sichuan University https://orcid.org/0000-0002-9632-7221

Research article

Keywords: total knee arthroplasty, cemented, cementless, revision, aseptic loosing

Posted Date: March 12th, 2020

DOI: https://doi.org/10.21203/rs.2.21176/v2

License: (c) (1) This work is licensed under a Creative Commons Attribution 4.0 International License. Read Full License 


\section{Abstract}

Background: Whether the cement could be given up in total knee arthroplasty (TKA) was still in controversy. We perform this meta-analysis to compare the rate of revision and functional recovery between two kinds of fixation in TKA.

Methods: Randomized controlled trials (RCTs), prospective/retrospective observational studies from PubMed (on 2019 Sep), EMBASE (on 2019 Sep), and the Cochrane Central Register of Controlled Trials (CENTRAL) and Web of Science (on 2019 Sep) were searched. Continuous outcomes were presented as mean difference or standard mean difference with $95 \% \mathrm{Cl}$ and discontinuous outcomes were reported as relative risk (RR) with $95 \% \mathrm{Cl}$. Random-effects or fixedeffects model was conducted to analyze the extracted data. The PRISMA guidelines and Cochrane Handbook were adopted to assess the quality of the results reported in included studies to ensure that the results of our meta-analysis were reliable and veritable. The continuous and dichotomous outcome were collected in a standard form, and the data were analysed by using Review Manager 5.3 software. Finally, the results were presented in the Forest plots. The rate of revision and reasons caused revision was the primary outcome of our study.

Results: Twenty-six studies involving 2369 patients in cementless TKA and 2654 patients in cemented TKA were finally included in our meta-analysis. 26 studies were divided into three subgroups according to the length of follow-up. The studies in the first subgroup followed less than 5.5 years, the second followed less than 10.5 years, and the third followed more than 10.5 years. Cementless fixation significantly decreased the rate of aseptic loosing ( $p=0.0002)$ and revision $(p=0.0002)$ in the first subgroup. Other reasons such as periprosthetic joint infection (PJI), instability and polyethylene wear were not significantly different between two groups. Significantly better functional recovery was got in cementless TKA in terms of Knee Society Function Score ( $p=0.01)$ when followed longer than 8.5 years. Significantly less patients in cementless group require manipulation under anesthesia $(p=0.02)$ when duration was longer than 5.5 years. However, there was no significant difference regarding the rate of complication between two kinds of fixation in TKA.

Conclusion: Not only the rate of aseptic loosing was decreased, rate of revision was also significantly decreased in cementless TKA within 5.5 years. In addition, the cementless TKA seemed performed better in postoperative functional recovery when had a long-term follow-up. However, the rate of complication was not significantly different in two kinds of fixation in TKA.

\section{Background}

As the gold standard of fixation method in total knee arthroplasty (TKA), cemented fixation occupied 93.5\% implants of TKA in 2010 [1]. There were a series of advantages in conventional cemented fixation in TKA. Firstly, cemented fixation allows for small bone cut defects, which was less technically challenging compared with uncemented fixation [2]. Secondly, cemented fixation could deliver antibiotics into the joint to prevent infection [3]. Thirdly, as an effective barrier, cement could insulate the polyethylene debris from the articular surface and prevent the osteolysis [4]. Therefore, most likely because the greater clinical experience with cemented fixation and better clinical results over cementless fixation, cemented fixation was still most used in TKA. An analysis using New Zealand Joint Registry (NZJR) data revealed that most (91.5\%) were fully cemented with $4.8 \%$ hybrid and $3.7 \%$ uncemented in 96,519 primary TKAs from 1998 to 2017 [5].

However, accompanied with the increasing demanding of TKA, the mean age of patients underwent TKA was decreasing [6]. It was predicted that more than half of patients underwent TKA was contributed by patients younger than 65 years-old by 2030 [6]. This posed a difficulty to the development of TKA, for the more active lifestyle was needed by younger patients. Therefore, the concern of bone resorption in the bone-cement interface would make the dominance of cemented fixation challenging [7]. Although the preliminary results of cementless fixation was proved discouraging, cementless TKA in young patients was found to have comparable midterm results to cemented TKA [8]. With a biologic bone-implant interface, cementless fixation determined to prevent the osteolysis and reduce the risk of aseptic loosening, especially in young patients with enough bone stock. Therefore, with development of prosthesis design and material renovation, cementless TKA has been introduced to extend the life of prosthesis [9].

In recent years, many studies and several meta-analysis have compared cemented with cementless fixation in terms of implant survival, functional recovery and radiological differences. However, there was not still a widely-accepted conclusion formed whether the cement should be used in TKA. To our knowledge, the length of follow-up was an important factor influenced the revision rate of TKA. While there was still no review and meta-analysis divided the studies according to length of follow-up to compare two kinds of fixation. Therefore, we divided the studies included in our meta-analysis into three groups to explore the revision rate and reasons of revision in two groups. We hypothesized that the cementless fixation was not inferior than cemented TKA in terms of revision rate and functional recovery.

\section{Methods}

The guidelines listed in the Preferred Reporting Items for Systematic Reviews and Meta-Analyses (PRISMA) was the basis of this systematic review and metaanalysis [10].

\section{Search strategy}

MEDLINE (1950 to date), PubMed (1966 to date), EMBASE (1974 to date), the Cochrane Central Register of Controlled Trials, the Wanfang database (1982 to date), and the Web of Science were systematically searched for studies on cementless fixation in total knee arthroplasty on Aug 30, 2019. "Knee, knee replacement, knee arthroplasty, total knee replacement, TKR, total knee arthroplasty, TKA," and "cementless, cemented, uncemented" were used as key words in connection with AND or OR. Meta-analyses were identified and screened out of the search results by the third reviewer. Then, the references of these metaanalyses were screened to find additional relevant studies. Another reviewer tried to contact expert informants by email to search for unpublished studies Finally, two reviewers independently assessed the studies, and any discrepancies were resolved by a discussion with the other reviewers. 
Studies were included according to the PICOS criteria: (1) Population: patients experiencing TKA who were demographically alike; (2) Intervention and Control: cementless and cemented fixation in TKA; (3) Outcomes: revision rate, reasons of revision, functional recovery, and rate of complication; (4) Study design: randomized controlled trial (RCT), prospective or retrospective observational studies.

Studies were excluded if: (1) relevant outcomes were missing or (2) the quality assessment was low $(\mathrm{RCT}<5$, non-RCTs<20) [11,12]. $(3)$ the groups in study was not fully-cementless and fully cemented, that the hybrid fixation was not included in this study.

\section{Quality assessment}

A modified seven-point JADAD scale was adopted to assess the methodological quality of the RCTs [11]. The scale considers five items, namely, randomization, concealment of allocation, double blinding, withdrawals and dropouts [11]. Based on the Cochrane Handbook, two reviewers independently evaluated the quality of the included RCTs. There was no disagreement between the two reviewers' ratings.

Two reviewers evaluated the quality of non-RCTs by using Methodological Index for Non-Randomized Studies scale (MINORS), which has a range of scores from 0 to 24 [12]. Unified consensus was obtained if there were any different opinions.

\section{Data extraction}

The relevant data, including the authors, year of publication, country, baseline information of participants, prosthesis design, revision rate, power analysis, the length of follow-up were independently extracted by two reviewers using a standard data extraction form.

To compare the two kinds of fixation in TKA, the outcomes were summarized in three parts. The first part was the rate of revision and reasons of revision, which was the primary outcome of our study. The second part was the postoperative functional recovery, including the Knee Society (KSS) knee and function scores, Oxford knee scores, range of motion (ROM), and manipulation under anesthesia. The third part was the rate of complication, including deep vein thrombosis (DVT) and all infection (superficial wound infection and periprosthetic joint infection).

\section{Statistical analysis}

The Review manager 5.3 (Nordic Cochrane Center, Copenhagen, Denmark) was used to perform the meta-analysis. The final results are shown in Forest plots. Mean differences (MD) or standard mean differences (SMD) were used to weigh the effect size for continuous outcomes, and relative risks (RR) were used for dichotomous outcomes. The $\mathrm{I}^{2}$ statistic was used to test for heterogeneity across the included studies [11]. A $p$ value $\leq 0.1$ or an $I^{2}>50 \%$ was regarded as proof of heterogeneity. A random-effects model is used to synthesize results with high heterogeneity and is more conservative than a fixed effects model. Therefore, a random-effects model was used to alleviate the effect caused by high heterogeneity, and a fixed effects model was used when statistical evidence showed low heterogeneity.

\section{Results}

\section{Search results}

As shown in Fig.1, among 1787 articles were obtained from the databases via the search strategy. After removing duplicates, 767 articles were screened. From among them 722 articles were removed after reading the title and abstract based on the inclusion criteria. Then, 19 studies were excluded on the basis of exclusion criteria (the reasons were offered in the supplementary material). Finally, 11 RCTs [2,13-22]and 15 non-RCTs [23-37] were included in this study after meeting the inclusion and exclusion criteria.

\section{Baseline information and quality assessment}

26 studies involving 2369 patients in cementless group and 2654 patients in cemented group were divided into three subgroups according to the length of follow-up. The length of follow-up $\leq 5.5$ years including 17 studies [14-18,20,21,23-25,27,29,31,32,35-37], which ranged from 2 to 5.3 years. The length of follow-up $\leq 10.5$ years including 6 studies $[13,19,26,28,30,33]$, which ranged from 5.7 to 10.2 years. The length of follow-up $>10.5$ years including 3 studies [2,22,34], which ranged from 12.1 to 16.6 years. The baseline information including study design, demographical data, revision rate, prosthesis and length of follow-up were clearly listed in Table 1. Especially, the duration of follow-up was same for cemented and cementless replacements in studies included.

The JADAD score of 11 RCTs were listed in Table 2 , both of them were $\geqq 5$, four of them $[2,15,21,22]$ got 7 points. The MINORS scores of 15 non-RCTs were listed in Table 3, both of them were $\geqq 20$, only one of them [37] got 24 points.

\section{Rate of revision and reasons of revision}

A total of 22 studies involving 2178 patients in cementless group and 2442 patients in cemented group reported the rate of revision during the follow-up. There were 101(4.6\%) and 131 (5.3\%) patients in two groups underwent the revision surgery for all kinds of reasons. Among of them, aseptic loosing was the most common reason of revision, next was the periprosthetic joint infection (PJI). The specific number of revisions and all kinds of reasons were listed in Table 4 in detail. In addition, we made a heat-map based on the risk ratio of revision caused by all kinds of reasons in every study (Fig.2). We divided 22 studies into three subgroups according to the length of follow-up and reported results as following:

First subgroup: follow-up $\mathbf{5} 5.5$ years

Page 3/16 
Among 14 studies involving 1251 patients in cementless group and 1450 patients in cemented group followed $\leq 5.5$ years reported the rate of revision between cementless and cemented fixation in TKA. There were $32(2.6 \%)$ and $72(5 \%)$ patients in two groups revised, patients in cemented group significantly increased the rate of revision compared with cementless group ( $\mathrm{RR}=0.47,95 \% \mathrm{Cl}$ : $[0.32,0.70], \mathrm{P}=0.0002$; Fig.3). It was important to note that two non-RCTs showed high rates of revision in the cemented group, the others didn't. Although the 12 was $35 \%$ with low heterogeneity, we also looked forward to more RCTs could be included in this topic in future research to prove the presence of difference.

8 of 14 studies involving 878 patients in cementlesss group and 1092 patients in cemented group reported the rate of revision caused by aseptic loosing. There were $8(0.6 \%)$ and $35(2.4 \%)$ patients in two groups revised for aseptic loosing, patients in cemented group significantly increased the rate of revision caused by aseptic loosing compared with cementless group (RR=0.28, 95\% Cl: [0.14, 0.54], P=0.0002; Fig.4).

11 of 14 studies involving 1080 patients in cementlesss group and 1270 patients in cemented group reported the rate of revision caused by periprosthetic joint infection (PJI). There were $11(0.9 \%)$ and $11(0.8 \%)$ patients in two groups revised for PJI, and no significant difference between two groups (RR=1.07, 95\% Cl: [0.51, 2.22], $P=0.86 ;$ Fig.5).

\section{Second subgroup: follow-up $\leq 10.5$ years}

Among 5 studies involving 697 in cementless group and 762 in cemented group followed $\leq 10.5$ years reported the rate of revision between cementless and cemented fixation in TKA. There were 62 (8.9\%) and 49 (6.4\%) patients in two groups revised, which was not significantly different between two groups (RR=1.22, 95\% Cl: [0.85, 1.77], P=0.28; Fig.3).

All 5 studies involving 697 patients in cementlesss group and 762 patients in cemented group reported the rate of revision caused by aseptic loosing. There were 38 (5.5\%) and 22 (2.9\%) patients in two groups revised for aseptic loosing, no significant difference between groups (RR=1.61, 95\% Cl: [0.96, 2.72], $\mathrm{P}=0.07$; Fig.4).

All 5 studies involving 697 patients in cementlesss group and 762 patients in cemented group reported the rate of revision caused by periprosthetic joint infection (PJI). There were9 (1.3\%) and 16 (2.1\%) patients in two groups revised for PJI, and no significant difference between two groups (RR=0.59, 95\% Cl: $[0.26,1.34], P=0.20 ;$ Fig.5).

\section{Third subgroup: follow-up $>10.5$ years}

Among 3 studies involving 230 patients in cementless group and 230 patients in cemented group followed>10.5 years reported the rate of revision between cementless and cemented fixation in TKA. There were 7 (3\%) and 10 (4.3\%) patients in two groups revised, which was not significantly different between two groups (RR=0.73, 95\% Cl: [0.30, 1.76 ], P=0.48; Fig.3).

All 3 studies involving 230 patients in cementlesss group and 230 patients in cemented group reported the rate of revision caused by aseptic loosing. There were $4(1.7 \%)$ and $6(2.6 \%)$ patients in two groups revised for aseptic loosing, no significant difference between two groups (RR=0.71, 95\% Cl: [0.23, 2.22], $\mathrm{P}=0.56$; Fig.4).

Only 1 study involving 100 patients in cementlesss group and 100 patients in cemented group reported the rate of revision caused by periprosthetic joint infection (PJI). There were $0(0 \%)$ and $1(1 \%)$ patients in two groups revised for PJI.

\section{Functional recovery}

12 studies involving 652 patients in cementlesss group and 656 patients in cemented group recorded the Knee Society knee score. They were divided into two subgroups according to if the duration of follow-up was $>\mathbf{5 . 5}$ years. Pooled results revealed there was no significant difference regarding Knee Society knee score between two groups in all subgroups (Fig.6A).

9 studies involving 827 patients in cementlesss group and 819 patients in cemented group recorded the Knee Society function score. There was no significant difference in short duration subgroup. While patients in cementless group had a better Knee Society function score when followed longer than $\mathbf{8 . 5}$ years $(\mathrm{MD}=1.77,95 \% \mathrm{Cl}$ : [0.36, 3.17], $\mathrm{P}=0.01$; Fig.6B).

5 studies involving 230 patients in cementlesss group and 221 patients in cemented group recorded the Oxford knee score, all of them followed shorter than $\mathbf{5 . 5}$ years. Pooled results revealed that fixation method didn't make a difference on Oxford knee score in short duration (Fig.6C).

7 studies involving 626 patients in cementlesss group and 679 patients in cemented group reported the range of motion (ROM) following TKA. Pooled results revealed the ROM was not significantly different even when the patients followed longer (Fig.7A). However, 7 studies involving 566 patients in cementlesss group and 588 patients in cemented group revealed that the rate of manipulation under anesthesia was significantly more in cemented group when the duration longer than 5.5 years (RR=0.41, 95\% Cl: [0.19, 0.87], P=0.02; Fig.7B).

\section{Complications}

5 studies involving 369 patients in cementlesss group and 390 patients in cemented group recorded the rate of deep vein thrombosis (DVT) following TKA. All of duration of follow-up were shorter than $\mathbf{5 . 5}$ years. There were 17 (4.6\%) in cementless group and 27 (6.9\%) in cemented group diagnosed as DVT, while it was not significantly different (Fig.8A). 
20 studies involving 2048 patients in cementlesss group and 2337 patients in cemented group recorded the rate of all infection following TKA. There were 29 $(1.4 \%)$ in cementless group and $32(1.4 \%)$ in cemented group diagnosed as superficial wound infection or PJI. In all subgroups at three different time periods, the results were not significantly different (Fig.8B).

\section{Discussion}

Compared with the published review and meta-analysis [38-42], the most prominent advantage of our study was that we divided studies into three subgroups according to the length of follow-up and reduced the bias for revision rate caused by the length of follow-up.

Survivorship of prosthesis was the most important endpoint in TKA [43]. The rate of revision and reasons caused revision were primary outcomes of our study. Nearly each included study reported the number of revision and reasons caused revision. We found that the rate of revision was not significantly different when all studies were combined, but when data were combined in studies followed less than 5.5 years the cementless fixation TKA presented significant superiority. Although relatively longer follow-up was needed to compare the true difference regarding the rate of revision between two kinds of fixation in TKA. It has been revealed that $3 \%$ to $50 \%$ primary TKAs underwent revision within the first five years $[44,45]$. Therefore, we believe that even we could not get significant difference in all three subgroups, the results from this period of follow-up was very meaningful for the future research. In addition, a potential explanation of non-significant results in subgroups followed longer than 5.5 years was that less articles followed longer than 5.5 years in our systematic research.

From the Table 4 and Fig.2, we found that aseptic loosing was the most common reason caused revision after TKA in our study. A total of 22 studies involving 4620 patients reported 232(5.02\%) revision and at least 9 kinds of reasons caused revision. Among the nine reasons caused revision, rate of aseptic loosing was $113(2.45 \%)$, followed by the periprosthetic joint infection ( $\mathrm{PJI}, 48(1.04 \%))$, instability $(15,0.32 \%)$, exchange of tibia polyethylene insert ( $11,0.24 \%)$, periprosthetic fracture $(6,0.13 \%)$, polyethylene wear $(4,0.09 \%)$, patella dislocation $(4,0.09 \%)$, patellofemoral arthritis $(4,0.09 \%)$, stiffness $(3,0.06 \%)$ and other reasons $(23,0.5 \%)$. Consistent with the rate of revision, rate of aseptic loosing was significantly decreased in the cementless fixation group in the first subgroup. However, other 8 reasons including PJI was not significantly different between two kinds of fixation (Fig. 5 and supplementary material). Therefore, we could conclude that aseptic loosing was significantly easier happened in bone-cement interface in cemented fixation group and lead to revision within 5.5 years after TKA.

As the secondary outcome of our study, the postoperative functional recovery also showed significant difference between two kinds of fixation in TKA. In this study, we used Knee Society/Function Score, Oxford Knee Score, Western Ontario and McMaster Universities Osteoarthritis Index scores (WOMAC), range of motion (ROM) and manipulation under anesthesia to evaluate the difference on clinical recovery. On the one hand, patients in cementless group had better functional recovery in terms of Knee Function Score compared with cemented group when followed longer than 8.5 years. On the other hand, although ROM was not significantly different, there were significantly less patients in cementless group required manipulation under anesthesia. A possible explanation for the better recovery in cementless TKA was that relevant complications such as osteolysis, anterior knee pain was more common in cemented group. However, rate of complications including DVT and infection was not significantly different between two kinds of fixation in our study.

From the results of previous research, cementless TKA showed inferior clinical outcomes and survivorship compared with cemented component [14, 40]. However, along with the development of manufacture and biomaterials including highly porous metals, cross-linked polyethylene, and corrections in initial cementless designs, some recent publications show successful results in long-term follow-up of cementless fixation [46]. Interest on cementless fixation increased as more young patients underwent TKA. Moreover, cementless TKA presented lower revision rates compared with cemented fixation in morbidly obese patients [25]. A possible reason for this phenomenon was that greater stress was placed on the bone-implant interface when patients were more active or obese [47]. Therefore, inferior performance of cemented TKA in younger and obese patients made the advent of cementless an alternative way to offer longterm results.

In addition, a study published in 2019 compared the actual cost of a cemented and cementless total knee arthroplasty procedure concluded that the overall procedural cost of implanting a cementless TKA was less than implanting a cemented TKA [48]. Therefore, cost alone should not be a barrier to using cementless TKA.

There are some weaknesses in this review and meta-analysis. Firstly, there were small number of studies followed $>5.5$ years included in our study and we did not divide the RCT and non-RCT in our study. Secondly, the prosthesis design used in included studies were not totally same, which might increase bias, while the heterogeneity was not high in our outcomes. Thirdly, in the 26 studies included in our meta-analysis, there were only 11 RCTs included, which decreased the level of evidence of our study. Therefore, more high-level RCTs were needed in futrure research. Fourthly, outcomes regarding complication after TKA was relatively simple, more relevant outcomes such as instability, stiffness, dislocation and osteolysis should be paid attention in future research.

\section{Conclusion}

Not only the rate of aseptic loosing was decreased, rate of revision was also significantly decreased in cementless TKA within 5.5 years. In addition, the cementless TKA seemed performed better in postoperative functional recovery when had a long-term follow-up. However, the rate of complication was not significantly different in two kinds of fixation in TKA.

\section{Declarations}

Ethics approval and consent to participate: This article does not contain any studies with human participants or animals performed by any of the authors. 
Consent for publication: Author Yuan Liu, Author Yi Zeng, Author Yuangang Wu, Author Mingyang Li, and Author Huiqi Xie declare that they consent the publication of this review and meta-analysis.

Competing interests: Author Yuan Liu, Author Yi Zeng, Author Yuangang Wu, Author Mingyang Li, and Author Huiqi Xie declare that they have no conflict of interest.

Funding: This study was supported through grants from the National Natural Science Foundation of China (81974347), the Key Project of Sichuan Science \& Technology Department (2018SZ0223) and National Clinical Research Center for Geriatrics, West China Hospital Sichuan University (NO. Z20191008).

Author's contribution: The following authors have designed the study (SB), gathered the data (LY, LMy), analyzed the data (ZY, WYg), wrote the initial drafts (LY), and ensure the accuracy of the data and analysis (XHq, SB).

Acknowledgements. All authors agree with the publication of this study.

\section{Abbreviations}

total knee arthroplasty (TKA); Randomized controlled trials (RCTs); Cochrane Central Register of Controlled Trials (CENTRAL); confidence interval (CI); angle of motion (ROM); deep vein thrombosis (DVT); Mean differences (MD); standard mean differences (SMD); periprosthetic joint infection (PJI).

\section{References}

1. Matassi F, Carulli C, Civinini R, Innocenti M (2013) Cemented versus cementless fixation in total knee arthroplasty. Joints 1(3): 121

2. Kim YH, Park JW, Lim HM, Park ES (2014) Cementless and cemented total knee arthroplasty in patients younger than fifty five years. Which is better? Int Orthop 38(2): 297

3. Chiu FY, Chen CM, Lin CF, Lo WH (2002) Cefuroxime-impregnated cement in primary total knee arthroplasty: a prospective, randomized study of three hundred and forty knees. J Bone Joint Surg Am 84(5): 759

4. Freeman MA, Tennant R (1992) The scientific basis of cement versus cementless fixation. Clin Orthop Relat Res. (276): 19

5. Nugent M, Wyatt MC, Frampton CM, Hooper GJ (2019) Despite Improved Survivorship of Uncemented Fixation in Total Knee Arthroplasty for Osteoarthritis, Cemented Fixation Remains the Gold Standard: An Analysis of a National Joint Registry. J Arthroplasty 34(8): 1626

6. Kurtz SM, Lau E, Ong K, Zhao K, Kelly M, Bozic KJ (2009) Future young patient demand for primary and revision joint replacement: national projections from 2010 to 2030. Clin Orthop Relat Res 467(10): 2606

7. Naudie DD, Ammeen DJ, Engh GA, Rorabeck CH (2007) Wear and osteolysis around total knee arthroplasty. J Am Acad Orthop Surg 15(1): 53

8. Hungerford DS, Krackow KA, Kenna RV (1989) Cementless total knee replacement in patients 50 years old and under. Orthop Clin North Am 20(2): 131

9. Bassett RW (1998) Results of 1,000 Performance knees: cementless versus cemented fixation. J Arthroplasty 13(4): 409

10. A L, DG A, J T, C M, PC G, JP I, M C, PJ D, J K, BMJ MDJ. The PRISMA statement for reporting systematic reviews and meta-analyses of studies that evaluate healthcare interventions: explanation and elaboration. 339(undefined): b2700, 2009

11. Liberati A, Altman DG, Tetzlaff $\mathrm{J}$ and et al (2009) The PRISMA statement for reporting systematic reviews and meta-analyses of studies that evaluate healthcare interventions: explanation and elaboration. BMJ 339: b2700

12. Slim K, Nini E, Forestier D, Kwiatkowski F, Panis Y, Chipponi J (2003) Methodological index for non-randomized studies (minors): development and validation of a new instrument. ANZ J Surg 73(9): 712

13. Baker PN, Khaw FM, Kirk LM, Esler CN, Gregg PJ (2007) A randomised controlled trial of cemented versus cementless press-fit condylar total knee replacement: 15-year survival analysis. J Bone Joint Surg Br 89(12): 1608

14. Carlsson A, Bjorkman A, Besjakov J, Onsten I (2005) Cemented tibial component fixation performs better than cementless fixation: a randomized radiostereometric study comparing porous-coated, hydroxyapatite-coated and cemented tibial components over 5 years. Acta Orthop 76(3): 362

15. Fernandez-Fairen M, Hernandez-Vaquero D, Murcia A, Torres A, Llopis R (2013) Trabecular metal in total knee arthroplasty associated with higher knee scores: a randomized controlled trial. Clin Orthop Relat Res 471(11): 3543

16. Fricka KB, Sritulanondha S, McAsey CJ (2015) To Cement or Not? Two-Year Results of a Prospective, Randomized Study Comparing Cemented Vs. Cementless Total Knee Arthroplasty (TKA). J Arthroplasty 30(9 Suppl): 55

17. Fricka KB, McAsey CJ, Sritulanondha S (2019) To Cement or Not? Five-Year Results of a Prospective, Randomized Study Comparing Cemented vs Cementless Total Knee Arthroplasty. J Arthroplasty 34(7S): S183

18. Gao F, Henricson A, Nilsson KG (2009) Cemented versus uncemented fixation of the femoral component of the NexGen CR total knee replacement in patients younger than 60 years: a prospective randomised controlled RSA study. Knee16(3): 200

19. Khaw FM, Kirk LM, Morris RW, Gregg PJ (2002) A randomised, controlled trial of cemented versus cementless press-fit condylar total knee replacement. Ten-year survival analysis. J Bone Joint Surg Br 84(5): 658

20. McCaskie AW, Deehan DJ, Green TP, Lock KR, Thompson JR, Harper WM, Gregg PJ (1998) Randomised, prospective study comparing cemented and cementless total knee replacement: results of press-fit condylar total knee replacement at five years. J Bone Joint Surg Br 80(6): 971

21. Nam D, Lawrie CM, Salih R, Nahhas CR, Barrack RL, Nunley RM (2019) Cemented Versus Cementless Total Knee Arthroplasty of the Same Modern Design: A Prospective, Randomized Trial. J Bone Joint Surg Am 101(13): 1185

Page 6/16 
22. Park JW, Kim YH (2011) Simultaneous cemented and cementless total knee replacement in the same patients: a prospective comparison of long-term outcomes using an identical design of NexGen prosthesis. J Bone Joint Surg Br 93(11): 1479

23. Abu-Rajab RB, Watson WS, Walker B, Roberts J, Gallacher SJ, Meek RM (2006) Peri-prosthetic bone mineral density after total knee arthroplasty. Cemented versus cementless fixation. J Bone Joint Surg Br 88(5): 606

24. Anis HK, Ramanathan D, Sodhi N, Klika AK, Piuzzi NS, Mont MA, Higuera CA, Molloy RM (2019) Postoperative Infection in Cementless and Cemented Total Knee Arthroplasty: A Propensity Score Matched Analysis. J Knee Surg, doi: 10.1055/s-0039-1678678

25. Bagsby DT, Issa K, Smith LS, Elmallah RK, Mast LE, Harwin SF, Mont MA, Bhimani SJ, Malkani AL (2016) Cemented vs Cementless Total Knee Arthroplasty in Morbidly Obese Patients. J Arthroplasty 31(8): 1727

26. Boyle KK, Nodzo SR, Ferraro JT, Augenblick DJ, Pavlesen S, Phillips MJ (2018) Uncemented vs Cemented Cruciate Retaining Total Knee Arthroplasty in Patients With Body Mass Index Greater Than 30. J Arthroplasty 33(4): 1082

27. Dodd CA, Hungerford DS, Krackow KA (1990) Total knee arthroplasty fixation. Comparison of the early results of paired cemented versus uncemented porous coated anatomic knee prostheses. Clin Orthop Relat Res. (260): 66

28. Duffy GP, Berry DJ, Rand JA (1998) Cement versus cementless fixation in total knee arthroplasty. Clin Orthop Relat Res (356): 66

29. Kamath AF, Lee GC, Sheth NP, Nelson CL, Garino JP, Israelite CL (2011) Prospective results of uncemented tantalum monoblock tibia in total knee arthroplasty: minimum 5-year follow-up in patients younger than 55 years. J Arthroplasty 26(8): 1390

30. Karachalios T, Komnos G, Amprazis V, Antoniou I, Athanaselis S (2018) A 9-Year Outcome Study Comparing Cancellous Titanium-Coated Cementless to Cemented Tibial Components of a Single Knee Arthroplasty Design. J Arthroplasty 33(12): 3672

31. Miller AJ, Stimac JD, Smith LS, Feher AW, Yakkanti MR, Malkani AL (2018) Results of Cemented vs Cementless Primary Total Knee Arthroplasty Using the Same Implant Design. J Arthroplasty 33(4): 1089

32. Pap K, Vasarhelyi G, Gal T, Nemeth G, Abonyi B, Hangody LR, Hangody GM, Hangody L (2018) Evaluation of clinical outcomes of cemented vs uncemented knee prostheses covered with titanium plasma spray and hydroxyapatite: A minimum two years follow-up. Eklem Hastalik Cerrahisi 29(2): 65

33. Pecina M, Djapic T, Haspl M (2000) Survival of cementless and cemented porous-coated anatomic knee replacements: retrospective cohort study. Croat Med J 41(2): 168

34. Prudhon JL, Verdier R (2017) Cemented or cementless total knee arthroplasty? - Comparative results of 200 cases at a minimum follow-up of 11 years. SICOT J 3: 70

35. Rand JA (1991) Cement or cementless fixation in total knee arthroplasty? Clin Orthop Relat Res (273): 52

36. Rosenberg AG, Barden RM, Galante JO (1990) Cemented and ingrowth fixation of the Miller-Galante prosthesis. Clinical and roentgenographic comparison after three- to six-year follow-up studies. Clin Orthop Relat Res (260): 71

37. Sinicrope BJ, Feher AW, Bhimani SJ, Smith LS, Harwin SF, Yakkanti MR, Malkani AL (2019) Increased Survivorship of Cementless versus Cemented TKA in the Morbidly Obese. A Minimum 5-Year Follow-Up. J Arthroplasty 34(2): 309

38. Hu B, Chen Y, Zhu H, Wu H, Yan S (2017) Cementless Porous Tantalum Monoblock Tibia vs Cemented Modular Tibia in Primary Total Knee Arthroplasty: A Meta-Analysis. J Arthroplasty 32(2): 666

39. Newman JM, Sodhi N, Dekis JC, Khlopas A, Piuzzi NS, Sultan AA, Levin JM, Mont MA (2019) Survivorship and Functional Outcomes of Cementless versus Cemented Total Knee Arthroplasty: A Meta-Analysis. J Knee Surg

40. Gandhi R, Tsvetkov D, Davey JR, Mahomed NN (2009) Survival and clinical function of cemented and uncemented prostheses in total knee replacement: a meta-analysis. J Bone Joint Surg Br 91(7): 889

41. Zhou K, Yu H, Li J, Wang H, Zhou Z, Pei F (2018) No difference in implant survivorship and clinical outcomes between full-cementless and full-cemented fixation in primary total knee arthroplasty: A systematic review and meta-analysis. Int J Surg 53: 312

42. Chen C, Li R (2019) Cementless versus cemented total knee arthroplasty in young patients: a meta-analysis of randomized controlled trials. J Orthop Surg Res. 14(1): 262

43. Mont MA, Pivec R, Issa K, Kapadia BH, Maheshwari A, Harwin SF (2014) Long-term implant survivorship of cementless total knee arthroplasty: a systematic review of the literature and meta-analysis. J Knee Surg 27(5): 369

44. Gioe TJ, Killeen KK, Grimm K, Mehle S, Scheltema K (2004) Why are total knee replacements revised?: analysis of early revision in a community knee implant registry. Clin Orthop Relat Res (428): 100

45. Dalury DF, Pomeroy DL, Gorab RS, Adams MJ (2013) Why are total knee arthroplasties being revised? J Arthroplasty 28(null): 120

46. Ritter MA, Meneghini RM (2010) Twenty-year survivorship of cementless anatomic graduated component total knee arthroplasty. J Arthroplasty 25(4): 507

47. Brown TE, Harper BL, Bjorgul K (2013) Comparison of cemented and uncemented fixation in total knee arthroplasty. Orthopedics. $36(5)$ : 380

48. Lawrie CM, Schwabe M, Pierce A, Nunley RM, Barrack RL (2019) The cost of implanting a cemented cementless total knee arthroplasty. Bone Joint J 101B(7_Supple_C): 61

\section{Tables}

Table 1 The baseline information of studies compared cementless with cement fixation in TKA 


\begin{tabular}{|c|c|c|c|c|c|c|c|c|c|c|}
\hline \multirow[b]{2}{*}{ studies } & \multirow[b]{2}{*}{ country } & \multirow[b]{2}{*}{$\begin{array}{c}\text { study } \\
\text { design }\end{array}$} & \multicolumn{5}{|c|}{ cementless/cement } & \multirow[b]{2}{*}{ prosthesis } & \multirow[b]{2}{*}{$\begin{array}{c}\text { power } \\
\text { analysis }\end{array}$} & \multirow[b]{2}{*}{$\begin{array}{l}\text { follow- } \\
\text { up }\end{array}$} \\
\hline & & & cases & age & BMI & female & $\begin{array}{l}\text { revision } \\
\text { rate(\%ם }\end{array}$ & & & \\
\hline follow-up $\leqq 5.5 y$ & & & & & & & & & & \\
\hline Abu-rajab2006 & UK & non-RCT & $20 / 18$ & $69 / 71$ & - & $11 / 8$ & - & - & $\mathrm{Y}$ & $2 y$ \\
\hline Anis2019 & USA & non-RCT & $133 / 132$ & $60 / 62$ & $33 / 33$ & $51 / 44$ & $2.3 / 1.5$ & - & $\mathrm{N}$ & $2 y$ \\
\hline Bagsby2016 & USA & non-RCT & $145 / 154$ & $62.7 / 58.8$ & $44.7 / 45.6$ & $102 / 122$ & $0.7 / 13$ & $\begin{array}{l}\text { Stryker } \\
\text { Triathlon }\end{array}$ & $\mathrm{N}$ & $3.65 y$ \\
\hline Carlsson2005 & Sweden & RCT & $27 / 29$ & $74 / 72$ & - & $20 / 22$ & $3.7 / 0$ & PFC & $\mathrm{N}$ & $5 y$ \\
\hline Dodd1990 & UK & non-RCT & $18 / 18$ & - & - & $15 / 15$ & $5.6 / 5.6$ & PCA & $\mathrm{N}$ & $5 y$ \\
\hline $\begin{array}{l}\text { Fernandez- } \\
\text { Fairen2013 }\end{array}$ & Switzerland & RCT & $74 / 71$ & $61 / 60$ & $29.1 / 30.5$ & $55 / 54$ & $0 / 1.6$ & NexGen CR & $\mathrm{Y}$ & $5 y$ \\
\hline Fricka2015 & USA & RCT & $47 / 46$ & $60.2 / 58.6$ & $31.4 / 32.7$ & $29 / 33$ & $2.1 / 2.2$ & NexGen CR & $\mathrm{Y}$ & $2 y$ \\
\hline Fricka2019 & USA & RCT & $41 / 44$ & $59.8 / 58.4$ & $31.4 / 31.9$ & $26 / 31$ & $4.9 / 2.3$ & NexGen CR & $\mathrm{Y}$ & $5 y$ \\
\hline Gao2009 & Sweden & RCT & $19 / 22$ & - & - & - & $5.3 / 0$ & NexGen CR & $\mathrm{Y}$ & $2 y$ \\
\hline Kamath2011 & USA & non-RCT & $100 / 312$ & $55 / 63$ & - & - & $2 / 1.6$ & NexGen CR & $\mathrm{N}$ & $5 y$ \\
\hline McCaskie1998 & UK & RCT & $58 / 81$ & $70.2 / 68.8$ & - & $32 / 49$ & - & $\mathrm{PFC}$ & $\mathrm{N}$ & $5 y$ \\
\hline Miller2017 & USA & non-RCT & $200 / 200$ & $64.3 / 64.4$ & 33.9/33.1 & $125 / 125$ & $3.5 / 4$ & $\begin{array}{l}\text { Stryker } \\
\text { Triathlon }\end{array}$ & $\mathrm{N}$ & $5.3 y$ \\
\hline Nam2019 & USA & RCT & $76 / 65$ & $61.3 / 63$ & $31.1 / 31.3$ & $36 / 34$ & $0 / 1.5$ & $\begin{array}{l}\text { Stryker } \\
\text { Triathlon }\end{array}$ & Y & $2 y$ \\
\hline Pap2018 & Hungary & non-RCT & $134 / 140$ & $59 / 69$ & & $53 / 64$ & $1.5 / 1.4$ & SanatSwing & $\mathrm{N}$ & $2 y$ \\
\hline Rand1991 & USA & non-RCT & $59 / 59$ & $57 / 66$ & $29.4 / 24.4$ & $24 / 25$ & - & $\mathrm{PFC}$ & $\mathrm{N}$ & $2.8 \mathrm{y}$ \\
\hline Rosenberg1990 & USA & non-RCT & $132 / 139$ & $59 / 70$ & & $77 / 82$ & $4.5 / 5.8$ & - & $\mathrm{N}$ & $3.6 y$ \\
\hline Sinicrope2018 & USA & non-RCT & $108 / 85$ & $62 / 60$ & $45.6 / 45$ & $82 / 67$ & $4.63 / 25.88$ & $\begin{array}{l}\text { Stryker } \\
\text { Triathlon }\end{array}$ & Y & $5 y$ \\
\hline follow-up $\leqq 10.5 y$ & & & & & & & & & & \\
\hline Baker2007 & UK & RCT & $224 / 277$ & $71 / 70$ & & $103 / 121$ & $8.9 / 8.7$ & $\mathrm{PFC}$ & $\mathrm{N}$ & $8.7 y$ \\
\hline Boyle2017 & USA & non-RCT & $154 / 171$ & $59.6 / 64.9$ & $37.4 / 37.4$ & $97 / 128$ & $3.9 / 3.5$ & $\begin{array}{l}\text { Stryker } \\
\text { Triathlon }\end{array}$ & $\mathrm{N}$ & $5.7 y$ \\
\hline Duffy1998 & USA & non-RCT & $55 / 51$ & $54 / 65$ & $29.07 / 27.63$ & $23 / 24$ & $16.4 / 5.9$ & PFC & $\mathrm{N}$ & $10.2 y$ \\
\hline Karachalios2018 & Greek & non-RCT & $54 / 54$ & $63.2 / 63.8$ & $32 / 31.5$ & $36 / 37$ & - & aMP system & $\mathrm{Y}$ & 8.6y \\
\hline Khaw2002 & UK & RCT & $177 / 219$ & $71 / 70$ & - & $103 / 121$ & $3.95 / 4.11$ & $\mathrm{PFC}$ & $\mathrm{N}$ & $7.3 y$ \\
\hline Pecina2000 & Croatia & non-RCT & $87 / 44$ & $57 / 62$ & - & - & $22.99 / 15.91$ & PCA & $\mathrm{N}$ & 7.3y \\
\hline follow-up>10.5y & & & & & & & & & & \\
\hline Kim2014 & Korea & RCT & $80 / 80$ & $54.3 / 54.3$ & $27.8 / 27.8$ & $63 / 63$ & $1.25 / 0$ & NexGen CR & $\mathrm{Y}$ & $16.6 y$ \\
\hline Park2011 & Korea & RCT & $50 / 50$ & $58.4 / 58.4$ & $26.6 / 26.6$ & $39 / 39$ & $2 / 0$ & NexGen CR & $\mathrm{Y}$ & $13.6 y$ \\
\hline Prudhon2017 & France & non-RCT & $100 / 100$ & $72.3 / 73.2$ & - & $57 / 59$ & $5 / 10$ & $\begin{array}{c}\text { NEW } \\
\text { WAVETM }\end{array}$ & $\mathrm{N}$ & $12.1 \mathrm{y}$ \\
\hline
\end{tabular}

RCT-randomized controlled trial; BMI-body mass index; PFC-Press-Fit Condylar; PCA-porous-coated anatomic; CRcruciate-retaining;

Table 2 The quality assessment of RCTs

\begin{tabular}{lccccc}
\hline studies & randomization & $\begin{array}{c}\text { concealment } \\
\text { of allocation }\end{array}$ & double blinding & $\begin{array}{l}\text { withdrawal } \\
\text { and dropout }\end{array}$ & Total score \\
\hline Baker2007 & 1 & 2 & 2 & 1 & 6 \\
Carlsson2005 & 2 & 2 & 1 & 1 & 6 \\
\hline Fernandez-Fairen2013 & 2 & 2 & 2 & 1 & 7 \\
\hline Fricka2015 & 2 & 2 & 1 & 1 & 6 \\
\hline Fricka2019 & 2 & 2 & 1 & 1 & 6 \\
\hline Gao2009 & 2 & 2 & 1 & 1 & 6 \\
\hline Khaw2002 & 1 & 2 & 2 & 1 & 6 \\
\hline Kim2014 & 2 & 2 & 2 & 1 & 7 \\
\hline McCaskie1998 & 1 & 2 & 1 & 1 & 5 \\
\hline Nam2019 & 2 & 2 & 2 & 1 & 7 \\
\hline Park2011 & 2 & 2 & 2 & 1 & 7 \\
\hline
\end{tabular}

Table 3 The quality assessment of non-RCTs 


\begin{tabular}{|c|c|c|c|c|c|c|c|c|c|c|c|c|}
\hline studies & $\begin{array}{c}\text { A } \\
\text { clearly } \\
\text { stated } \\
\text { aim }\end{array}$ & $\begin{array}{l}\text { Inclusion of } \\
\text { consecutive } \\
\text { patients }\end{array}$ & $\begin{array}{c}\text { Prospective } \\
\text { data } \\
\text { collection }\end{array}$ & $\begin{array}{l}\text { Endpoints } \\
\text { appropriate } \\
\text { to the aim } \\
\text { of the study }\end{array}$ & $\begin{array}{l}\text { Unbiased } \\
\text { assessment } \\
\text { of the study } \\
\text { endpoint }\end{array}$ & $\begin{array}{l}\text { A follow-up } \\
\text { period } \\
\text { appropriate } \\
\text { to the aims } \\
\text { of study }\end{array}$ & $\begin{array}{l}\text { Less } \\
\text { than } \\
5 \% \\
\text { loss to } \\
\text { follow- } \\
\text { up }\end{array}$ & $\begin{array}{c}\text { Prospective } \\
\text { calculation } \\
\text { of the } \\
\text { sample size }\end{array}$ & $\begin{array}{c}\text { An } \\
\text { adequate } \\
\text { control } \\
\text { group }\end{array}$ & $\begin{array}{c}\text { Contemporary } \\
\text { groups }\end{array}$ & $\begin{array}{c}\text { Baseline } \\
\text { equivalence } \\
\text { of groups }\end{array}$ & $\begin{array}{l}\text { Adeq } \\
\text { statis } \\
\text { anal }\end{array}$ \\
\hline Abu-rajab2006 & 2 & 2 & 2 & 2 & 2 & 2 & 0 & 2 & 2 & 2 & 2 & \\
\hline Anis2019 & 2 & 2 & 0 & 2 & 2 & 2 & 2 & 0 & 2 & 2 & 2 & \\
\hline Bagsby 2016 & 2 & 2 & 2 & 2 & 2 & 2 & 2 & 0 & 2 & 1 & 2 & \\
\hline Boyle2017 & 2 & 2 & 2 & 2 & 2 & 2 & 0 & 0 & 2 & 2 & 2 & \\
\hline Dodd1990 & 2 & 2 & 2 & 2 & 2 & 2 & 2 & 0 & 2 & 2 & 2 & \\
\hline Duffy1998 & 2 & 2 & 2 & 2 & 2 & 2 & 0 & 0 & 2 & 2 & 2 & \\
\hline Kamath2011 & 2 & 2 & 2 & 2 & 2 & 2 & 1 & 0 & 2 & 2 & 2 & \\
\hline Karachalios2018 & 2 & 2 & 2 & 2 & 2 & 2 & 2 & 2 & 2 & 0 & 2 & \\
\hline Miller2017 & 2 & 2 & 2 & 2 & 2 & 2 & 2 & 0 & 2 & 2 & 2 & \\
\hline Pap2018 & 2 & 2 & 2 & 2 & 2 & 2 & 2 & 0 & 2 & 2 & 2 & \\
\hline Pecina2000 & 2 & 2 & 2 & 2 & 2 & 2 & 0 & 0 & 2 & 2 & 2 & \\
\hline Prudhon2017 & 2 & 2 & 2 & 2 & 2 & 2 & 2 & 0 & 2 & 0 & 2 & \\
\hline Rand1991 & 2 & 2 & 2 & 2 & 2 & 2 & 2 & 0 & 2 & 2 & 2 & 2 \\
\hline Rosenberg1990 & 2 & 2 & 2 & 2 & 2 & 2 & 2 & 0 & 2 & 2 & 2 & \\
\hline Sinicrope2018 & 2 & 2 & 2 & 2 & 2 & 2 & 2 & 2 & 2 & 2 & 2 & \\
\hline
\end{tabular}

Table 4 The specific number of revision caused by all kinds of reasons

\begin{tabular}{|c|c|c|c|c|c|c|c|c|}
\hline \multirow[b]{2}{*}{ studies } & \multirow[b]{2}{*}{ patients } & \multirow[b]{2}{*}{$\begin{array}{l}\text { number of } \\
\text { revisions }\end{array}$} & \multirow[b]{2}{*}{ aseptic loosing } & \multirow[b]{2}{*}{ PJI } & \multicolumn{4}{|c|}{ cementless/cement(number (\%)) } \\
\hline & & & & & instability & $\begin{array}{l}\text { polyethylene } \\
\text { wear }\end{array}$ & $\begin{array}{c}\text { exchange of } \\
\text { tibial } \\
\text { polyethylene } \\
\text { insert }\end{array}$ & $\overline{\mathrm{pe}}$ \\
\hline follow-up $\leqq 5.5 y$ & & & & & & & & \\
\hline Anis2019 & $133 / 132$ & $3 \square 2.3 \square / 2(1.5)$ & & $3 \llbracket 2.3 \square / 2(1.5)$ & & & & \\
\hline Bagsby2016 & $145 / 154$ & $1(0.7) / 20(13)$ & $0(0) / 9(5.8)$ & $1(0.7) / 2(1.3)$ & $0(0) / 3(1.9)$ & $0(0) / 1(0.6)$ & & \\
\hline Carlsson2005 & $27 / 29$ & $1(3.7) / 0(0)$ & & $1(3.7) / 0(0)$ & & & & \\
\hline Dodd1990 & $18 / 18$ & $1(5.6) / 1(5.6)$ & $1(5.6) / 1(5.6)$ & & & & & \\
\hline $\begin{array}{l}\text { Fernandez- } \\
\text { Fairen2013 }\end{array}$ & $71 / 64$ & $0(0) / 1(1.6)$ & & $0(0) / 1(1.6)$ & & & & \\
\hline Fricka2015 & $47 / 46$ & $1(2.1) / 1(2.2)$ & & $0(0) / 1(2.2)$ & $1(2.1) / 0(0)$ & & & \\
\hline Fricka2019 & $41 / 44$ & $2 \square 4.9 \square / 1(2.3)$ & $1(2.4) / 0(0)$ & $0(0) / 1(2.3)$ & & & & 1 \\
\hline Gao2009 & $19 / 22$ & $1(5.3) / 0(0)$ & & & & & & \\
\hline Kamath2011 & $100 / 312$ & $2(2) / 5(1.6)$ & $0(0) / 2(0.6)$ & $0(0) / 2(0.6)$ & $1(1) / 0(0)$ & & & \\
\hline Miller2017 & $200 / 200$ & $7(3.5) / 8(4)$ & $1(0.5) / 5(2.5)$ & $1(0.5) / 0(0)$ & $2(1) / 2(1)$ & & & \\
\hline Nam2019 & $76 / 65$ & $0(0) / 1(1.5)$ & & $0(0) / 1(1.5)$ & & & & \\
\hline Pap2018 & $134 / 140$ & $2(1.5) / 2(1.4)$ & $2(1.5) / 2(1.4)$ & & & & & \\
\hline Rosenberg1990 & $132 / 139$ & $6(4.5) / 8(5.8)$ & $2(1.5) / 0(0)$ & $1(0.8) / 0(0)$ & $0(0) / 2(1.4)$ & & & \\
\hline Sinicrope2018 & $108 / 85$ & $5(4.63) / 22(25.88)$ & $1(0.93) / 16(18.82)$ & $4(3.7) / 1(1.18)$ & $0(0) / 2(2.35)$ & $0(0) / 1(1.18)$ & & \\
\hline total & $1251 / 1450$ & $32(2.6) / 72(5)$ & $8(0.6) / 35(2.4)$ & $11(0.9) / 11(0.8)$ & $4(0.3) / 9(0.6)$ & $0(0) / 2(0.1)$ & & 1 \\
\hline follow-up $\leqq 10.5 y$ & & & & & & & & \\
\hline Baker2007 & $224 / 277$ & $20(8.9) / 24(8.7)$ & $12(5.4) / 14(5)$ & $4(1.8) / 7(2.5)$ & $2(0.9) / 0(0)$ & $0(0) / 1(0.4)$ & $2(0.9) / 2(0.7)$ & \\
\hline Boyle2017 & $154 / 171$ & $6(3.9) / 6(3.5)$ & $2(1.3) / 1(0.6)$ & $1(0.6) / 2(1.2)$ & & & & \\
\hline Duffy1998 & $55 / 51$ & $9(16.4) / 3(5.9)$ & $8(14.5) / 2(3.9)$ & $0(0) / 1(2)$ & & & & \\
\hline Khaw2002 & $177 / 219$ & $7(3.95) / 9(4.11)$ & $3(1.69) / 1(0.46)$ & $1(0.56) / 5(2.28)$ & & $0(0) / 1(0.46)$ & $3(1.69) / 2(0.91)$ & \\
\hline Pecina2000 & $87 / 44$ & 20ロ22.99ロ/7(15.91) & $13(14.94) / 4(9.09)$ & $3(3.45) / 1(2.27)$ & & & $0(0) / 2(4.55)$ & 1 \\
\hline total & $697 / 762$ & $62(8.9) / 49(6.4)$ & $38(5.5) / 22(2.9)$ & $9(1.3) / 16(2.1)$ & $2(0.3) / 0(0)$ & $0(0) / 2(0.3)$ & $5(0.7) / 6(0.8)$ & 1 \\
\hline follow-up >10.5y & & & & & & & & \\
\hline Kim2014 & $80 / 80$ & $1(1.25) / 0(0)$ & $1(1.25) / 0(0)$ & - & & - & - & \\
\hline Park2011 & $50 / 50$ & $1(2) / 0(0)$ & $1(2) / 0(0)$ & & & & & \\
\hline Prudhon2017 & $100 / 100$ & $5(5) / 10(10)$ & $2(2) / 6(6)$ & $0(0) / 1(1)$ & & & & \\
\hline total & $230 / 230$ & $7(3) / 10(4.3)$ & $4(1.7) / 6(2.6)$ & $0(0) / 1(0.4)$ & & & & 31 \\
\hline TOTAL & $2178 / 2442$ & $101(4.6) / 131(5.3)$ & $50(2.3) / 63(2.6)$ & $20(0.9) / 28(1.1)$ & $6(0.3) / 9(0.4)$ & $0(0) / 4(0.2)$ & $5(0.2) / 6(0.3)$ & 5( \\
\hline $\begin{array}{l}\text { Rate of } \\
\text { revision }\end{array}$ & 4620 & $232(5.02)$ & $113(2.45)$ & $48(1.04)$ & $15(0.32)$ & $4(0.09)$ & $11(0.24)$ & \\
\hline
\end{tabular}

PJI- periprosthetic joint infection

\section{Figures}



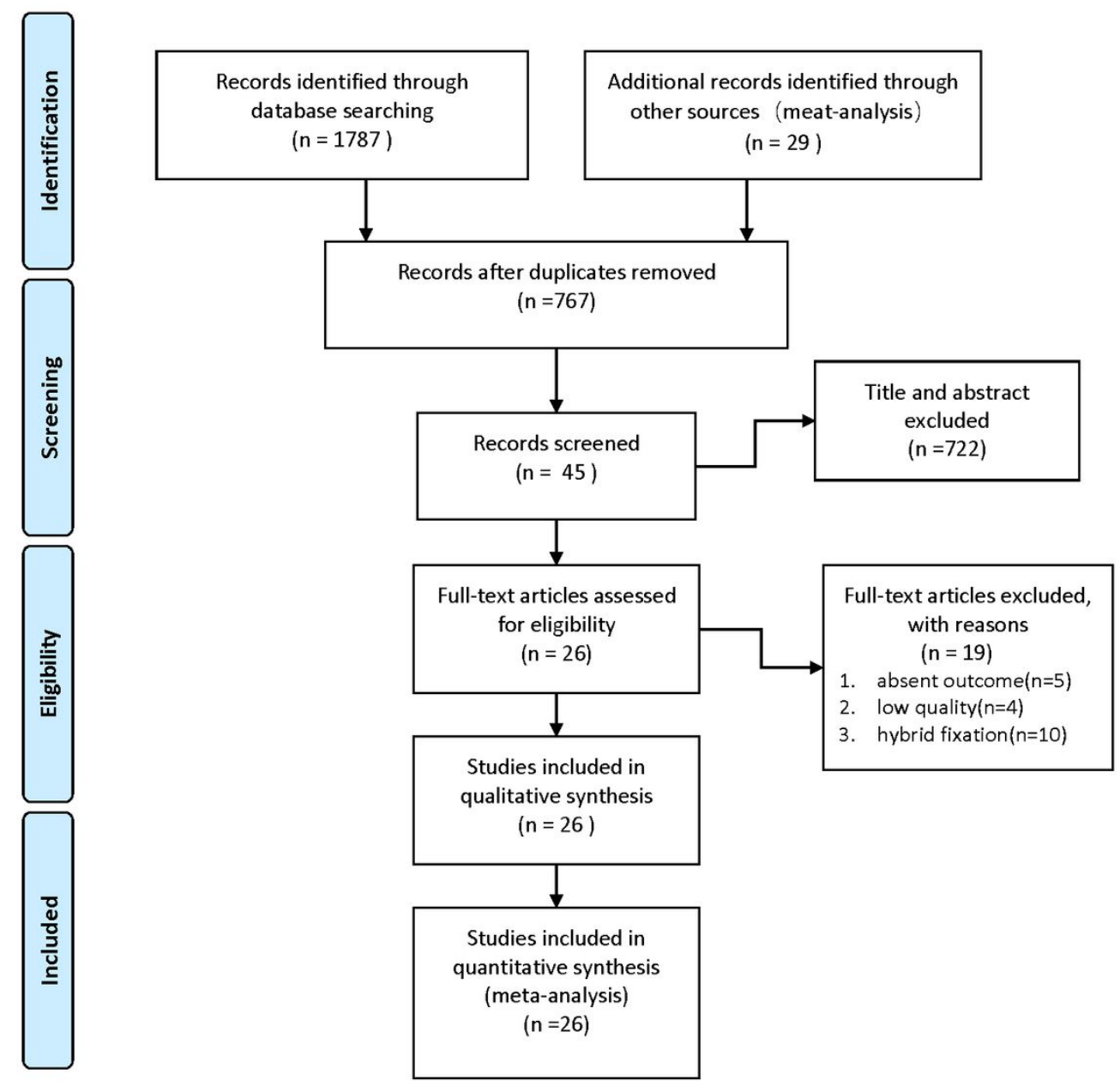

Figure 1

The flowchart of the study selection 


\begin{tabular}{|c|c|c|c|c|c|c|c|c|c|c|}
\hline studies & $\begin{array}{l}\text { aseptic } \\
\text { loosing }\end{array}$ & PJ & instability & $\begin{array}{c}\text { polyethylene } \\
\text { wear }\end{array}$ & $\begin{array}{l}\text { exchange of tibial } \\
\text { polyethylene } \\
\text { insert }\end{array}$ & $\begin{array}{l}\text { periprost } \\
\text { hetic } \\
\text { fracture }\end{array}$ & $\begin{array}{l}\text { patella } \\
\text { dislocation }\end{array}$ & $\begin{array}{c}\text { Patellofemoral } \\
\text { arthritis }\end{array}$ & stiffness & $\begin{array}{l}\text { other } \\
\text { reasons }\end{array}$ \\
\hline \multicolumn{11}{|l|}{ follow-up $\leqq 5.5 y$} \\
\hline Anis2019 & & 1.49 & & & & & & & & \\
\hline Bagsby2016 & 0.06 & 0.53 & 0.15 & 0.35 & & & & 0.15 & 0.21 & \\
\hline Carlsson 2005 & & 3.21 & & & & & & & & \\
\hline Dodd1990 & 1 & & & & & & & & & \\
\hline Fernandez-Fairen 2013 & & 0.3 & & & & & & & & \\
\hline Fricka2015 & & 0.33 & 2.94 & & & & & & & \\
\hline Fricka2019 & 3.21 & 0.36 & & & & 3.21 & & & & \\
\hline Gao2009 & & & & & & & & & & 3.65 \\
\hline Kamath2011 & 0.62 & 0.62 & 9.3 & & & & & & & 3.14 \\
\hline Miller2017 & 0.2 & 3 & 1 & & & & 3.02 & & & 2.01 \\
\hline Nam2019 & & 0.29 & & & & & & & & \\
\hline Pap2018 & 1.04 & & & & & & & & & \\
\hline Rosenberg1990 & 5.26 & 3.16 & 0.21 & & & & & & & 0.52 \\
\hline Sinicrope 2018 & 0.05 & 3.15 & 0.16 & 0.26 & & & & 0.26 & & \\
\hline \multicolumn{11}{|l|}{ follow-up $\leqq 10.5 y$} \\
\hline Baker2007 & 1.06 & 0.71 & 6.18 & 0.41 & 1.24 & & & & & \\
\hline Boyle2017 & 2.22 & 0.56 & & & & & & & & 1.11 \\
\hline Duffy1 998 & 3.71 & 0.31 & & & & & & & & 2.83 \\
\hline Khaw2002 & 3.71 & 0.25 & & 0.41 & 1.86 & & & & & \\
\hline Pecina 2000 & 1.64 & 1.52 & & & 0.1 & 1.53 & 3.69 & & & \\
\hline \multicolumn{11}{|l|}{ follow-up $>10.5 y$} \\
\hline Kim2014 & 3 & & & - & - & & & & & \\
\hline Park2011 & 3 & & & & & & & & & \\
\hline Prudhon 2017 & 0.33 & 0.33 & & & & 3 & & & 0.33 & 0.33 \\
\hline
\end{tabular}

Figure 2

Heat-map regarding the risk ratio of rate of the revision and reasons in every study 


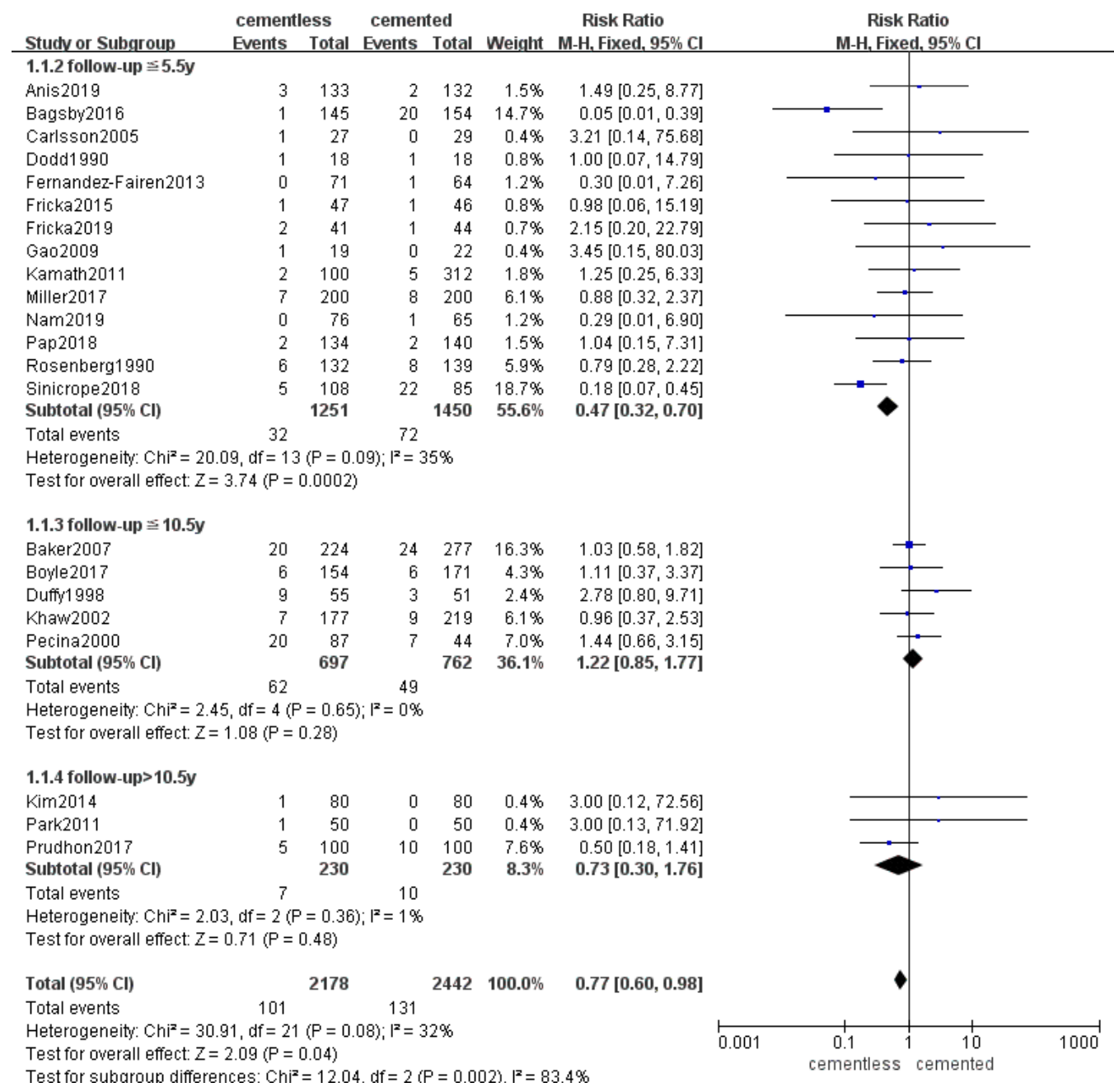

\section{Figure 3}

The frost blot about the rate of revision 
cementless cemented Risk Ratio

Risk Ratio

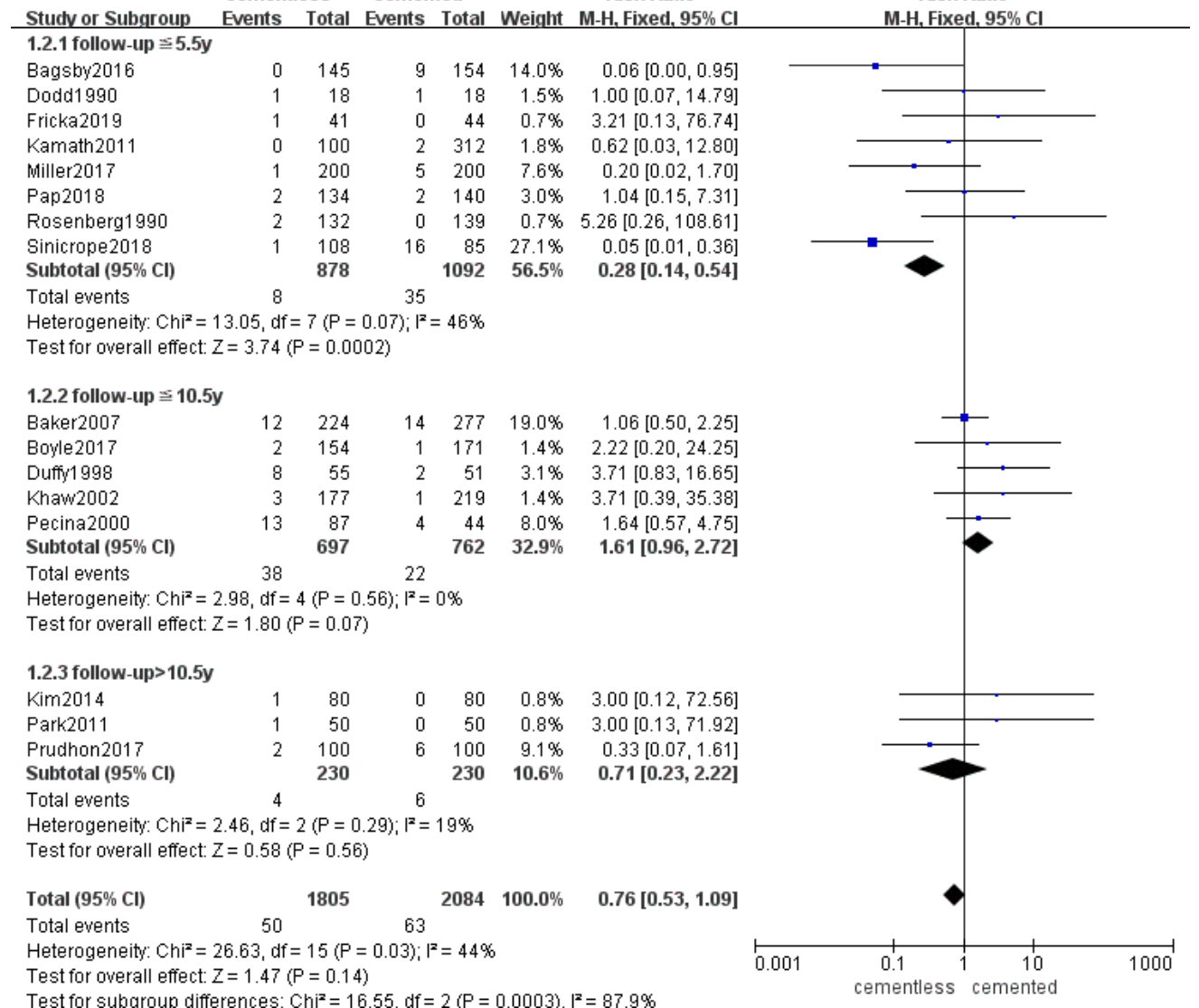

Test for subaroun differences: $\mathrm{Chi}^{2}=16.55 . \mathrm{df}=2(\mathrm{P}=0.0003) . \mathrm{I}^{2}=87.9 \%$

\section{Figure 4}

The frost blot about the rate of aseptic loosing

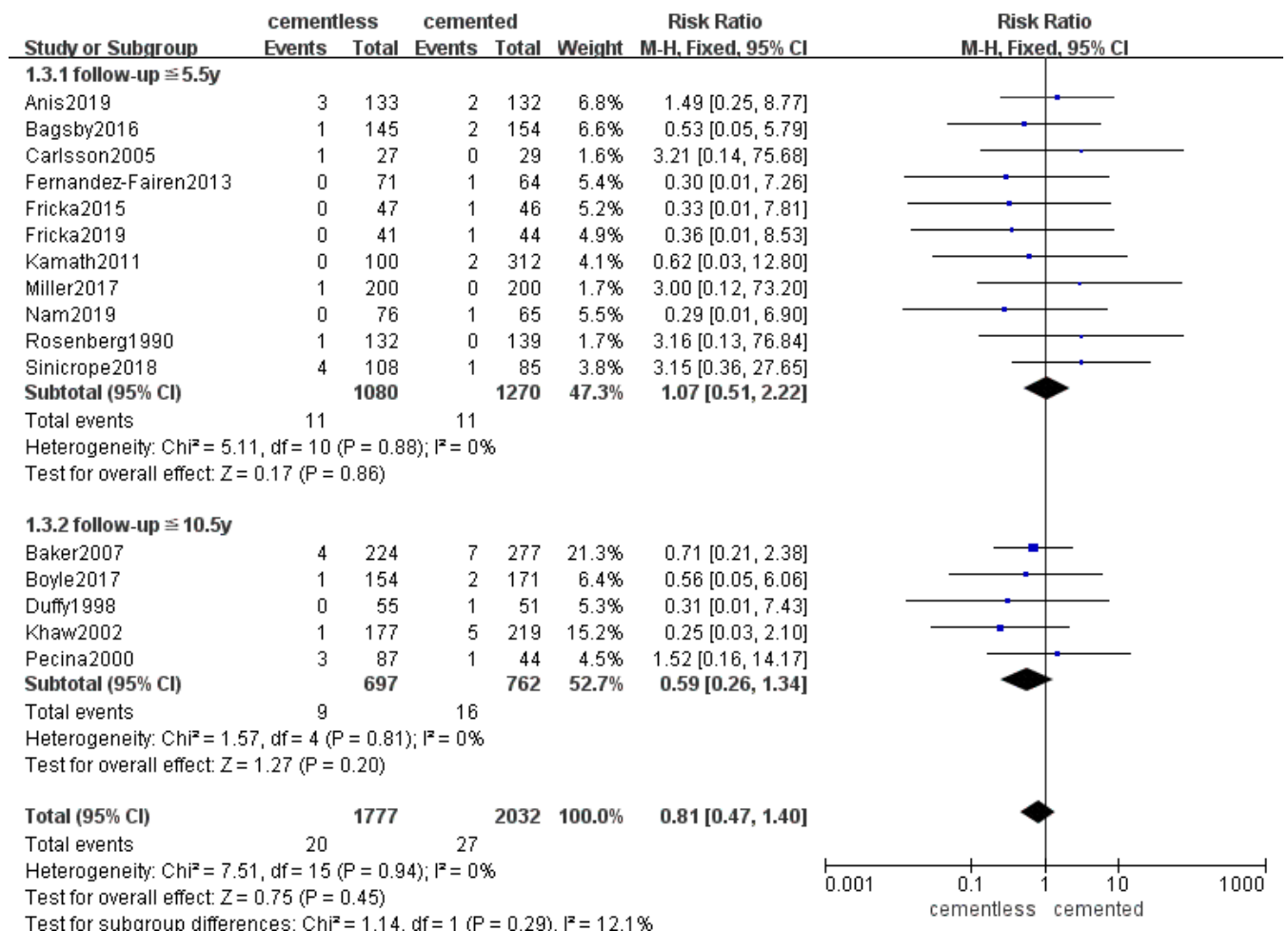

\section{Figure 5}

The frost blot about the rate of periprosthetic joint infection 
A. Knee Society knee scores

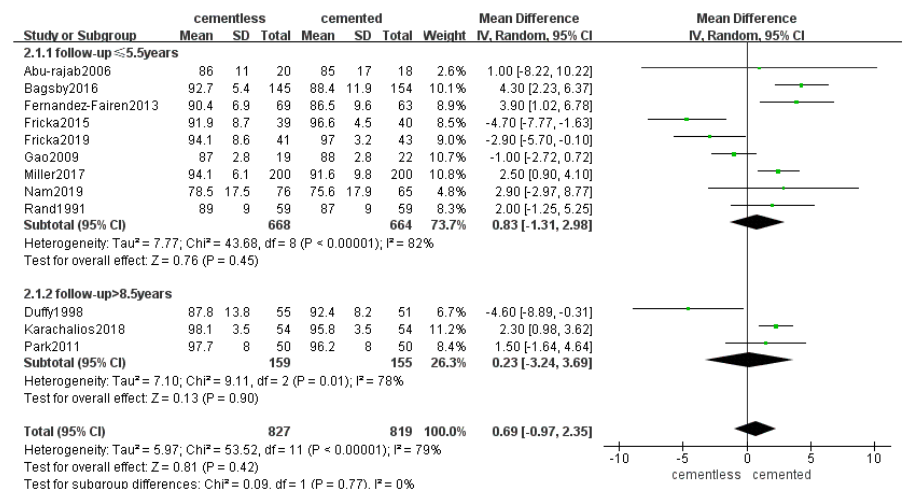

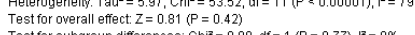

B. Knee Society function scores

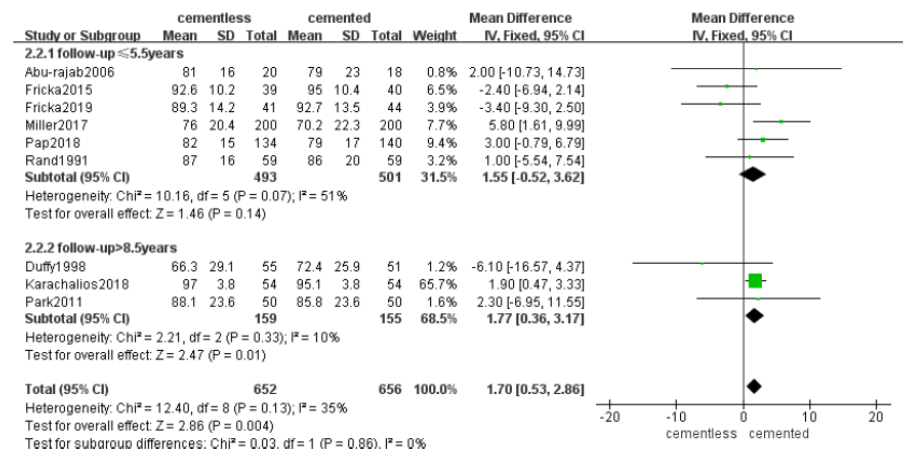

Test or overale entect. $z=2.86(P=0.004) \quad$.

C. Oxford knee score (follow-up $\leqslant 5.5$ years)

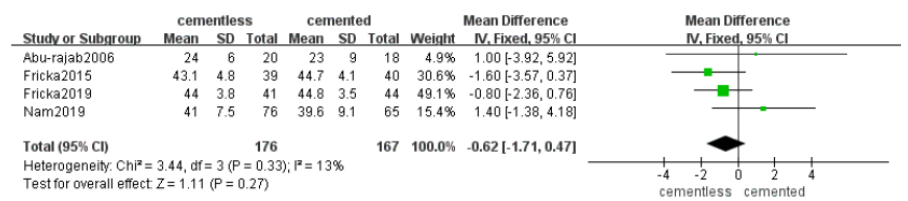

\section{Figure 6}

The frost blot about the functional recovery 


\section{A. Range of motion (ROM)}

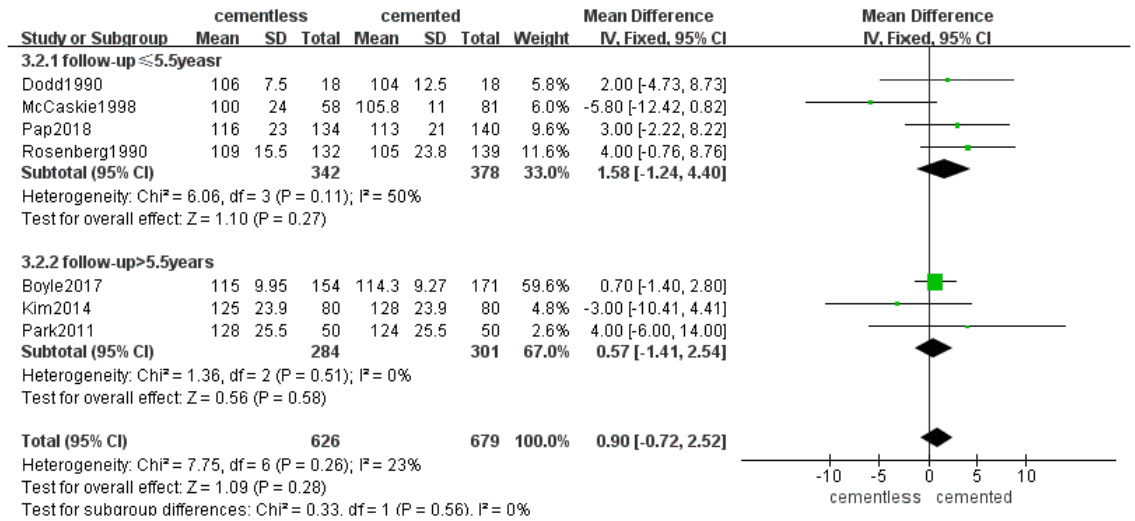

B. Manipulation under anesthesia

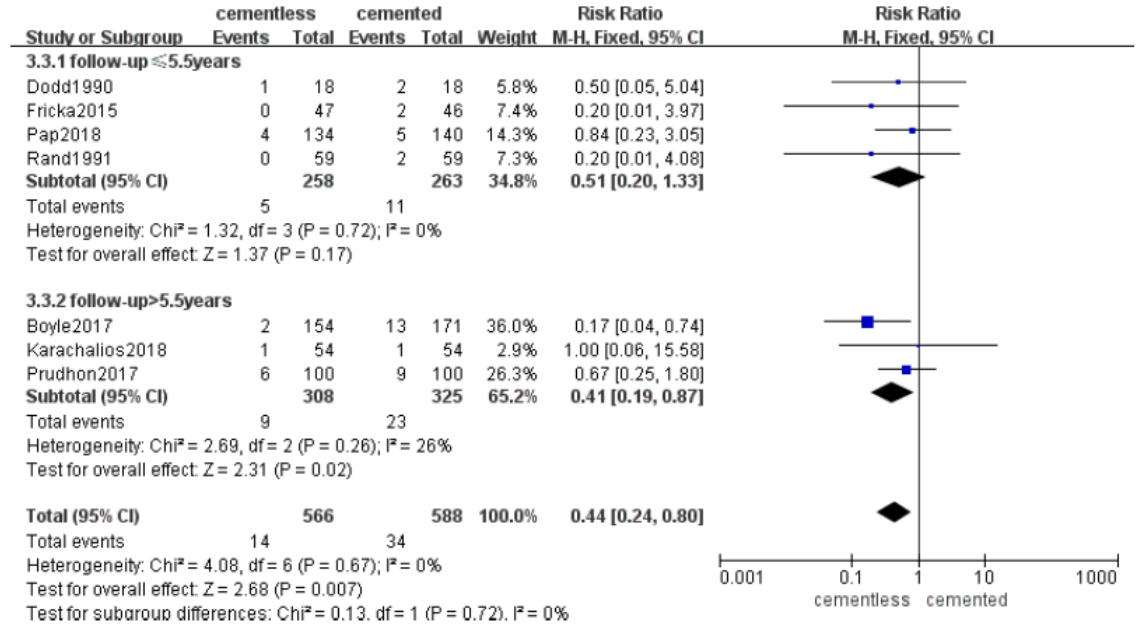

\section{Figure 7}

The frost blot about the knee motion 
A. Deep Vein Thrombosis (follow-up $\leqslant 5.5$ years)

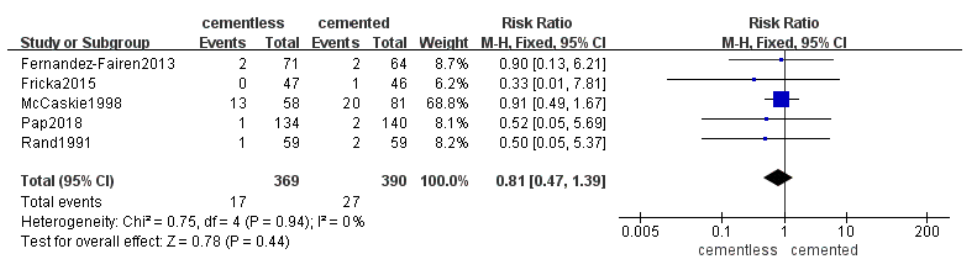

B. All Infection

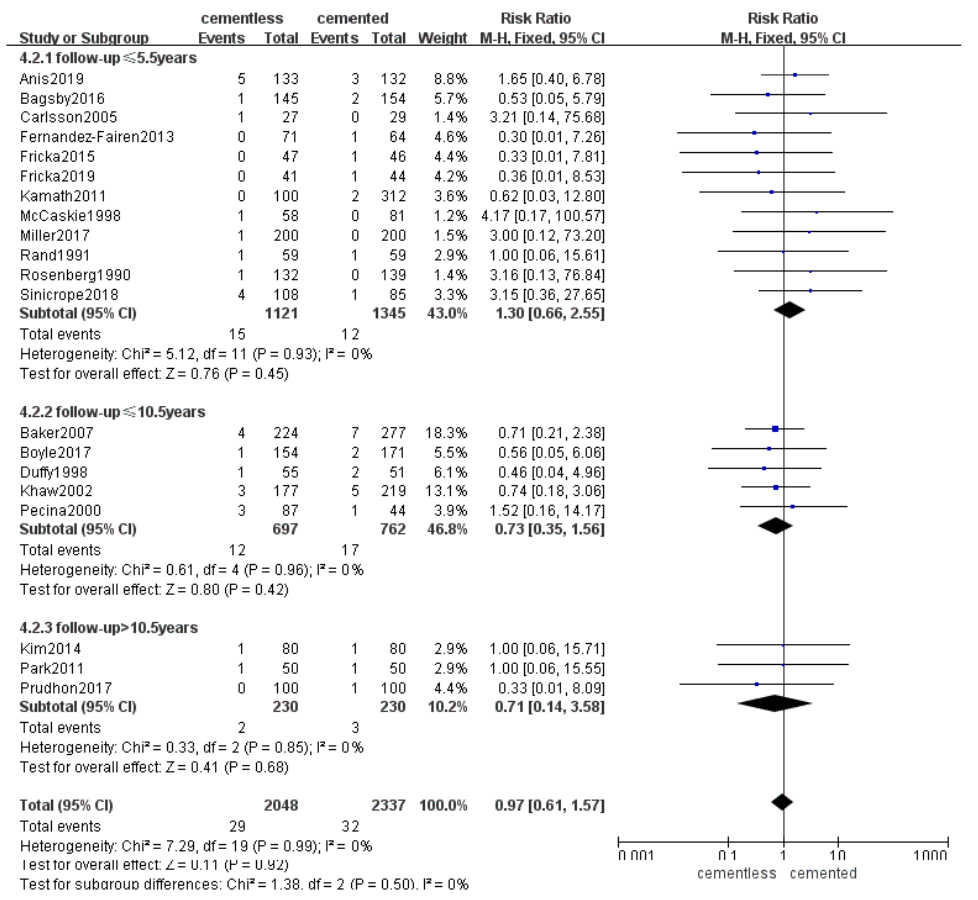

\section{Figure 8}

The frost blot about the rate of complications

\section{Supplementary Files}

This is a list of supplementary files associated with this preprint. Click to download.

- supplementarymaterial.doc 